L. Masiero, R. Maggi

Accounting for WTP/WTA discrepancy in discrete choice models : discussion of policy implications based on two freight transport stated choice experiments

Quaderno N. 11-03

Decanato della Facoltà di Scienze economiche

Via G. Buffi, $13 \mathrm{CH}-6900$ Lugano 


\title{
Accounting for WTP/WTA discrepancy in discrete choice models: Discussion of policy implications based on two freight transport stated choice experiments
}

\author{
Lorenzo Masiero \\ Rico Maggi \\ Istituto Ricerche Economiche (IRE) \\ Faculty of Economics \\ University of Lugano \\ Switzerland. \\ lorenzo.masiero@usi.ch,rico.maggi@usi.ch
}

Version 1.1: 29 September 2010

Paper presented at the Kuhmo-Nectar Conference on Transport Economics 2010, Valencia, July 2010

\begin{abstract}
A key input in cost-benefit analysis is represented by the marginal rate of substitution which expresses the willingness to pay, or its counterpart willingness to accept, for both market and non-market goods. The consistent discrepancy between these two measures observed in the literature suggests the need to estimate reference dependent models able to capturing loss aversion by distinguishing the value attached to a gain from the value attached to a loss according to reference dependent theory. This paper proposes a comparison of willingness to pay and willingness to accept measures estimated from models with both symmetric and reference dependent utility specifications within two different freight transport stated choice experiments. The results show that the reference dependent specification outperforms the symmetric specification and they prove the robustness of reference dependent specification over datasets designed according different attributes levels ranges. Moreover we demonstrate the policy relevance of asymmetric specifications illustrating the strong implications for cost-benefit analysis in two case studies.
\end{abstract}

Keywords: WTP/WTA discrepancy, freight choice, policy evaluation

\section{Introduction}


A key input in the economic evaluation of transport measures is represented by the marginal rate of substitution which expresses the willingness to pay (WTP), or its counterpart willingness to accept (WTA), for both market and non-market goods. Indeed, in the analysis of travel demand a lot of effort has been put into modelling individual preferences in order to obtain the trade-off between time and cost, commonly known as value of travel time saving (VTTS). In this context, Hensher (2001) reports that in the quantification of user benefits for transport project appraisal the VTTS accounts for 60 per cent. Mackie et al. (2001) indicate that around the 80 per cent of the monetised benefits within costbenefit analysis (CBA) is attributable to VTTS.

Revealed preferences (RP) and stated preferences (SP) are the main methods for collecting data suitable for the estimation of WTP and WTA measures within the discrete choice class of models (McFadden, 1974; Train et al., 1987; Ben-Akiva et al., 1993). In particular, stated choice experiments have become a consolidate instrument that allow for the analysis of individual preferences by letting the respondent choose among a set of hypothetical choice situations.

Increasing attention has been paid to generating experiment designs by pivoting the hypothetical situations around individual specific reference alternatives. However, the data collected are typically modelled in the same way as data collected from RP or non-pivoted SP. That is by letting the utility function be symmetric in respect to positive and negative deviations from the reference alternative levels. Within symmetric utility specification the WTA value results to be the mirror of the WTP value, which results in line within the Hicksian surplus theory in a context where WTP and WTA are small relative to the income (see Randall and Stoll, 1980 for a proof). However, the consistent discrepancy between WTP and WTA measures observed in the literature ${ }^{1}$ suggests the need to estimate asymmetric models able to capturing loss aversion by distinguishing the value attached to a gain from the value attached to a loss according to reference dependent theory (Kahneman and Tversky, 1979; Tversky and Kahneman, 1991; Tversky and Kahneman, 1992). In this regards, recent studies have analysed reference dependent utility specifications in a stated choice framework supporting the hypothesis that classic symmetric models tend to over-estimate WTP and under-estimate WTA (see for example, Hess et al. 2008; De Borger and Fosgerau, 2008; Masiero and Hensher, 2010). Indeed, the direct relationship between loss aversion and WTA/WTP discrepancy has been tested and proved in a laboratory experiment (Bateman el al., 1997) and in a stated choice experiment (De Borger and Fosgerau, 2008).

Although well recognized and discussed in several papers (see for example, Hanemann, 1991; Brown and Gregory, 1999; Graves, 2009a; Graves, 2009b) the divergence between WTP and WTA is not taken into account in the majority of the discrete choice models specification carrying potential upward biased estimates of WTP measures for policy makers. On the other hand, the estimation of reference dependent discrete choice models re-opens the debate on which measure between WTP and WTA is most desirable in the economic evaluation of transport projects.

In this paper we propose a comparison of WTA and WTP measures estimated from models with both symmetric and reference dependent utility specifications within two different freight transport stated choice experiments conducted among Swiss logistics managers in 2003 and 2008, respectively. In this context, the freight transport sector occupies a minor part in the research literature involving the transport sector in general. However, the impact of the value of freight transport time saving (VFTTS) in the evaluation of the profitability of investments in transport infrastructures must not be neglected

\footnotetext{
${ }^{1}$ A review by Horowitz and McConnell (2002) based on 45 studies sets the median of the ratio WTA/WTP to 2.6.
} 
since it can represent up to 50 per cent of the potential VTTS (Zamparini and Reggiani, 2007). In particular, we focus the analysis on proving the robustness of the loss aversion validity (and WTA/WTP divergence) within pivoted freight transport stated choice experiments defined under different experimental design assumptions. The results are based on the estimation of random parameters logit models on both the single dataset collected in 2003 and the pooled dataset containing the two stated choice experiments.

In the derivation of WTP and WTA measures, the selection of the density function for the random parameters has a great impact. Indeed, if all parameters are set as random then the estimation of the marginal rate of substitution involves the ratio of two random distributions which present substantial evaluation problems. Train and Weeks (2005) proposed the estimation of discrete choice models in WTP space overcoming the problem of ratio distributions by involving the WTP distribution directly in the model estimation. However, the estimation of models in WTP space requires the normalization of the model for the cost attribute. This is a restriction for reference dependent models that have two cost attributes, for gains and losses respectively (see Rose and Masiero, 2009). Masiero and Hensher (2010) specify a reference dependent model where the random parameters are assumed to be triangular distributed and constraining the standard deviation of the coefficient to be equal to the mean. Although the use of constrained triangular distribution leads to desirable estimates of the parameters since it avoids the estimation of irrational values (i.e. positive coefficient for cost and time), the heterogeneity across the sample is only assumed and not estimated. In order to analyse the spread of the random parameters distribution when respondent face with gains and losses we decide to fix the cost parameter and let the attribute associated to the other parameters to be Normal distributed. This method has good properties in terms of model identification, WTP estimation and rational assumption about the cost coefficient (see Revelt and Train, 2000).

A specific purpose of this paper is to discuss the policy implications that arise from the WTA/WTP discrepancy. In this context, we propose to reconsider the concept of WTP and WTA use in transport investment appraisal focusing the discussion on the rationale of using asymmetric WTP and WTA instead of symmetric WTP. We illustrate the argument with two hypothetical infrastructure investments, one for improvement of the current situation, the other for maintenance.

The paper is organized as follows. In section two we describe the two stated choice experiments used in the analysis. The methodological background is presented in section three whereas the models estimates are shown in section four along with comments on the results. In section five we outline the potential policy implications associated to WTA/WTP discrepancy. Conclusions and final remarks are provided in section six.

\section{Data}

The data refers to two freight transport stated choice experiments conducted among Swiss logistics managers in 2003 and 2008, S-2003 and S-2008 respectively. The first dataset referred to the evaluation of relevant service characteristics in freight transport (see Maggi and Rudel, 2008 for details) whereas the second dataset is part of a project ${ }^{2}$ aimed to analyze the infrastructure vulnerability

\footnotetext{
${ }^{2}$ NFP54 "Sustainable Development of the Built Environment", funded by the Swiss National Science Foundation.
} 
of the Gotthard corridor, one of the most important European transport corridors (see Masiero and Maggi 2009 for details).

The freight transport services considered in the two stated choice experiments are represented by conventional origin-destination services and they are expressed as function of cost (CHF per transport service), time (hours per transport service) and punctuality (percentage of transport services arriving on time per yearly). An additional attribute is considered in the first dataset expressing the yearly percentage of transport services which register damages to the goods transported.

Table 1 Description of the stated choice experiments

\begin{tabular}{lll}
\hline & \multicolumn{1}{c}{ DATASET S-2003 } & DATASET S-2008 \\
\hline Attributes and Levels & \multicolumn{1}{c}{ C } \\
\hline Transport Cost (CHF) & $-40 \%,-20 \%$, Reference, $+20 \%,+40 \%$ & $-10 \%,-5 \%$, Reference, $+5 \%,+10 \%$ \\
\hline Transport time (hours) & $-40 \%,-20 \%$, Reference, $+20 \%,+40 \%$ & $-10 \%,-5 \%$, Reference, $+5 \%,+10 \%$ \\
\hline Transport Punctuality ( $\%)$ & $96 \%, 98 \%, 100 \%$ & $96 \%, 98 \%, 100 \%$ \\
\hline Damages ( $\%)$ & $6 \%, 4 \%, 2 \%$ & \\
\hline Design & & Labeled \\
\hline Experiment & Unlabeled & Road, Piggyback and Combined transport \\
\hline Alternatives & Alternative A and Alternative B & Road \\
\hline Reference in Design & Not included & 15 \\
\hline Number of Choice tasks & 20 &
\end{tabular}

The hypothetical alternatives included in the designs of the two stated choice experiments have been created by pivoting the cost and time attributes levels around a reference alternative previously described by the logistics managers. Although logistics managers reported also reference values for punctuality and damages, these two attributes are presented in absolute values for technical convenience. The levels associated to each attributes in the two datasets are shown in Table 1 which also highlights the main differences between the two experimental designs ${ }^{3}$.

The collection of the data involved face-to-face interviews based on Computer Assisted Personal Interview (CAPI), where logistics managers were asked to indicate their preferred alternative in each choice task. For both the choice experiments, the sample focused on medium (50 to 249 employees) and large (more than 249 employees) companies. Regarding S-2003 data, 35 firms operating in the food and wholesale sector were represented and a subset of the sample answered to the same experiment twice, discriminating for inbound and outbound across the two experiments. After having removed the extreme cases (in terms of cost, time and punctuality values revealed by logistics managers) in order to obtain similar range of minimum and maximum values across the two samples, S-2003 data consists of 42 experiments, representing 840 choice observations. The sample associated to S-2008 data is composed of 27 firms operating in the manufacturing sector, representing 405 choice observations. By pooling the two datasets we obtain 69 valid experiments, representing 1245 choice observations. The descriptive statistics of the reference transport services described by logistics managers are reported in Table 2.

Table 2 Descriptive statistics for attributes of the reference transport service

\footnotetext{
${ }^{3}$ The attributes levels values for dataset S-2003 differ from those reported in the Table in Maggi and Rudel (2008) which by mistake are not correctly reported there.
} 


\begin{tabular}{lrrrrrrrrrr}
\hline Variable & \multicolumn{2}{c}{ Mean } & \multicolumn{2}{c}{ Median } & \multicolumn{2}{c}{ SD } & \multicolumn{2}{c}{ Min } & \multicolumn{2}{c}{ Max } \\
& S-2003 & S-2008 & S-2003 & S-2008 & S-2003 & S-2008 & S-2003 & S-2008 & S-2003 & S-2008 \\
\hline Cost (CHF) & 894.4 & 1300.1 & 800 & 1000 & 533.1 & 1152.9 & 120 & 136 & 2500 & 5400 \\
\hline Time (hr) & 15.1 & 33.3 & 7 & 24 & 26.3 & 27.3 & 2 & 2 & 168 & 96 \\
\hline Punctuality (\%) & 98.5 & 96.5 & 99 & 98 & 1.7 & 3.0 & 94 & 90 & 100 & 100 \\
\hline Damages (\%) & 0.3 & - & 0 & - & 0.6 & - & 0 & - & 2 & - \\
\hline
\end{tabular}

\section{Methodology}

Within the Random Utility Models (RUM) framework, the utility function associated with respondent $n$ for alternative $j$ in choice task $s$ is defined as the combination of a systematic component and an unobserved component, where the systematic part is assumed to be linear in parameters such that

$U_{n j s}=\alpha_{j}+\sum_{k=1}^{K} \beta_{n k} x_{n j s k}+\varepsilon_{n j s}$

where $\alpha_{j}$ represents the alternative specific constant, $\beta_{n k}$, is the vector of $k$ coefficients associated to the set of attributes, and the unobserved part, $\varepsilon_{\mathrm{njs}}$, is Independent and Identically Distributed (IID) extreme value type 1 . The subscript $n$ in $\beta_{n k}$ denotes the random parameters logit class of models, where the coefficients (all or a subset) are assumed to be heterogeneous across the respondents according to a specific density function. In this context, the Normal distribution is the most referred in the literature although log-normal and triangular distributions are also used (see Hensher and Greene, 2003).

The derivation of the marginal rate of substitution is straightforward and leads to WTP and WTA estimates. For symmetric specification models they are defined as follows:

$$
M R S=\frac{\frac{d}{d x_{n j k}} \beta_{n k} x_{n j s k}}{\frac{d}{d x_{n j s k}} \beta_{n k} x_{n j s k}} \Rightarrow W T P=-W T A=\frac{\beta_{n k}}{\beta_{n, \cos t}}
$$

As shown in Equation (2), symmetric models assume by construction that WTP and WTA are identical in the absolute values.

A deviation from the classic symmetric model specification, formulated in Equation (1), is represented by the reference dependence model specification which allows the estimation of different coefficients for both positive and negative deviations from the reference values. The utility function is then defined as follows:

$U_{n j s}=\alpha_{j}+\sum_{k=1}^{K} \beta_{n k}($ dec $) x_{n j s k}($ dec $)+\sum_{k=1}^{K} \beta_{n k}($ inc $) x_{n j s k}($ inc $)+\varepsilon_{n j s}$

where (dec) and (inc) indicate decreases and increases respectively, and $x_{n j s k}(\mathrm{dec})=\max \left(x_{r e f}-x_{j}, 0\right)$ and $x_{n j s k}($ inc $)=\max \left(x_{j}-x_{\text {ref }}, 0\right)$. The estimation of different parameters for gains and losses with respect 
to the reference values allows to test for asymmetries in the utility function ${ }^{4}$ and eventually to test for the presence of loss aversion. Moreover, the WTP and WTA measures are not forced to be symmetric anymore since they are separately estimated according to the following relation:

For undesirable goods: $W T P=\frac{\beta_{n k(d e c)}}{\beta_{n, \text { cost }(i n c)}} ; W T A=\frac{\beta_{n k(i n c)}}{\beta_{n, \text { cost }(d e c)}}$

For desirable goods: $W T P=\frac{\beta_{n k(i n c)}}{\beta_{n, \operatorname{cost}(\text { inc })}} ; W T A=\frac{\beta_{n k(d e c)}}{\beta_{n, \operatorname{cost}(\text { dec })}}$

The relationship between loss aversion and WTA/WTP divergence can then be easily proved from Equations (4) and (5). In fact, loss aversion holds if the absolute value of the coefficient associated to losses is bigger than the absolute value of the coefficient associated to gains. That is, for undesirable goods: $\left|\beta_{n k(i n c)}\right|>\left|\beta_{n k(d e c)}\right|$; whereas for desirable goods: $\left|\beta_{n k(d e c)}\right|>\left|\beta_{n k(i n c)}\right|$. If loss aversion holds for both goods in the numerator and the cost attribute then WTA $>$ WTP.

Given the panel structure of the data and the use of the random parameters logit class of models, the estimation of the utility parameters is derived from the maximization of the following simulated log likelihood:

$L L_{n}=\sum_{n} \ln \frac{1}{R} \sum_{r} \prod_{s} \frac{\exp \left(\boldsymbol{\alpha}_{j}+\boldsymbol{\beta}_{n}^{\prime} \mathbf{X}_{n j s}\right)}{\sum_{j} \exp \left(\boldsymbol{\alpha}_{j}+\boldsymbol{\beta}_{n}^{\prime} \mathbf{X}_{n j s}\right)}$

where $s=1, \ldots, S$ represent the number of choice situations whereas $r=1, \ldots, R$ refers to the number of draws ${ }^{5}$.

\section{Model results}

The estimation of symmetric and reference dependent models is performed firstly on the S-2003 data and then on a joint dataset, where we pooled S-2003 and S-2008 data (for model estimation based on S2008 see Masiero and Hensher $\left.(2010)^{6}\right)$. This allows us to test for robustness of reference dependent specification across different datasets. The estimation of the models for the pooled dataset includes also the computation of the scale parameters for the three alternatives of dataset S-2008 in order to take into account the difference in the scale associated to different datasets. In doing this, we normalize the scale of S-2003 dataset to one upon the second dataset ${ }^{7}$. The estimation of the models is based on 500 Halton draws and performed using Nlogit 4.

Table 3 Model results

M1

M2

M3

M4

\footnotetext{
${ }^{4}$ Note that the reference dependence specification nests the symmetric specification.

${ }^{5}$ Refer to Train (2003) for details.

${ }^{6}$ Note that Masiero and Hensher (2010) use constrained triangular distribution for random parameters whereas here we use unconstrained normal distributions for attribute parameters and a fixed cost coefficient.

${ }^{7}$ See Hensher (2008) for details.
} 


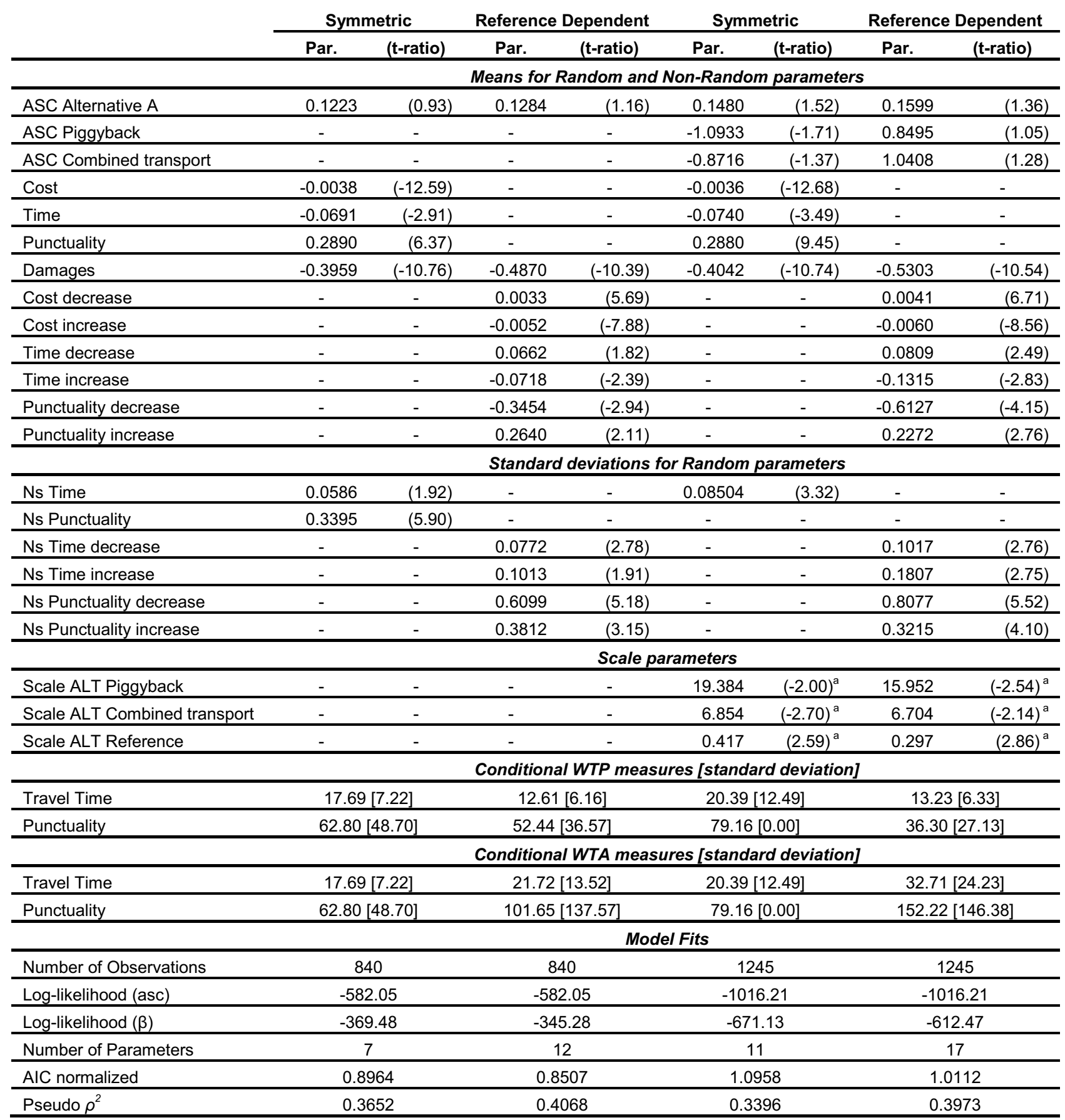

${ }^{\mathrm{a}}$ The t-ratio is calculated on the assumption that the scale parameter is different from one.

The model results are shown in Table 3. The first two columns (M1 and M2) refer to symmetric model specification and reference dependent model specification for S-2003 data whereas the last two columns (M3 and M4) refer to the same models specification but for the pooled dataset. The overall evaluation of model fits is based on the log-likelihood at convergence, the Akaike's Information Criterion (AIC) and the pseudo Rho-square ${ }^{8}$.

\footnotetext{
${ }^{8}$ Note that the pseudo $\rho^{2}$ is calculated as $(1-\mathrm{L}(\operatorname{asc}) / \mathrm{L}(\beta))$, where $\mathrm{L}(\operatorname{asc})$ refers to the log-likelihood function for the model estimated with alternative specific constants only whereas $\mathrm{L}(\beta)$ refers to the log-likelihood function at convergence.
} 
Comparing these three measures we register that the reference dependent model specification outperforms the symmetric one in both the datasets used. In particular, the pseudo $\rho^{2}$ rises from 0.3652 to 0.4068 for S-2003 data and from 0.3396 to 0.3973 for the pooled dataset. These findings exclude the hypothesis that the restricted symmetric models are more parsimonious than the unrestricted reference dependent models.

The scale parameters estimated for the alternatives of dataset S-2008 within the joint estimation result statistically different from 1 providing evidence for a significant difference in the scale of the two datasets used in the analysis. In particular, the scale parameters for piggyback and combined transport alternatives indicate that the unobserved effects are characterized by a considerably lower variance compared to dataset S-2003. On the contrary the unobserved effects associated to the reference alternative report a bigger variance if compared with the alternatives in dataset S-2003.

Examining the coefficient estimates for the symmetric models (M1 and M3) associated with the attributes we observe that they all are of the expected sign that is, negative for damages, cost and time attributes and positive for punctuality. Both mean and standard deviation (for random parameters) estimates result statistically significant at an alpha level of 0.05 except for the standard deviation of the time parameter in S-2003 data which results statistically significant at an alpha level of 0.10 . Looking at the reference dependent model specifications (M2 and M4), where cost, time and punctuality attributes are defined in terms of gains and losses, we observe a similar consistency. That is, parameters associated with gains (cost decrease, time decrease and punctuality increase) are positive in sign whereas the parameters associated with losses (cost increase, time increase and punctuality decrease) are negative in sign. Moreover, we find that loss aversion holds for all the three attributes and in both dataset specifications. In fact, the parameters associated with losses are in absolute value bigger than the parameters associated with gains. The standard deviation for the random parameters results higher for the parameters associated with losses meaning that the preferences of the logistics managers are more heterogeneous when logistics managers are faced with losses.

The conditional estimates for WTP measures from symmetric models are in line with current research literature (see Zamparini and Reggiani (2007) for a review). In particular, the willingness to pay for time is $17.7 \mathrm{CHF} /$ hour $^{9}$ and $20.4 \mathrm{CHF} /$ hour for symmetric models M1 and M3, respectively. The willingness to pay for punctuality is a key factor, as reported in similar studies (e.g., Danielis et al., 2005; Fowkes, 2007), for logistics managers who show a considerable sensitivity regarding punctuality of the transport service. For symmetric models the WTP for punctuality reaches $62.8 \mathrm{CHF}$ and 79.16 CHF per percentage point for M1 and M3, respectively.

Looking at the reference dependent model specifications in M2 and M4, we are able to distinguish between WTP and WTA. In particular, referring to the estimates for the pooled dataset (M4) we find that the WTP for time is $13.23 \mathrm{CHF} /$ hour whereas the WTA for time is $32.71 \mathrm{CHF} /$ hour. On the other hand, the WTP for punctuality is 36.30 CHF for an increase in punctuality by one percentage point whereas the WTA is 152.22 CHF for a decrease of punctuality of one percentage point. Punctuality still remains a crucial factor, especially when logistics managers are faced with a reduction of this service attribute. The WTA/WTP discrepancy registered is fairly marked for both the marginal rates of substitution considered. In this context, the ratio WTA/WTP is 2.5 for time and 4.2 for punctuality which results in line with past studies (see for example, Horowitz and McConnell (2002) for a review).

\footnotetext{
${ }^{9}$ Approximate monthly average exchange rate for April 2010, $1 \mathrm{CHF}=0.93$ USD.
} 


\section{Policy implications}

In the previous section we demonstrated how the estimation of reference dependent choice models leads to asymmetric estimates of WTP and WTA measures according to the research literature on WTA/WTP discrepancy. This has implications on policy evaluations since these measures are a key input in order to decide if a certain policy is economically convenient or not. Indeed, assuming that WTP and WTA values are not symmetric sets the discussion on the appropriate use of these measures. Different policy measures or infrastructure investments are designed for different purposes which imply either the use of WTP or WTA values. In this section we focus on infrastructure investments and in particular on transport projects, defining three categories according to the expected outcome of consumers WTP and WTA values.

In Table 4 we show the expected sign of consumers' WTP and WTA values associated with a new infrastructure depending on whether the impact on actual conditions represents a worsening, a conservation or an improvement in terms of consumers' utility. Infrastructures that lie in the worsening category are those which carry considerable environmental consequences such as the construction of a nuclear power station. In this case, the expected willingness to pay for having a new nuclear power station is expected to be negative whereas the willingness to accept is expected to be particularly high. Typically the calculation of the social impact associated to such infrastructures is based on ad-hoc stated choice experiments designed directly in the WTA space. Since in this paper we are interested in the economic appraisal of transport infrastructure investments we do not discuss this category any further.

Table 4 Expected consumers WTP and WTA values due to an infrastructure investment

\begin{tabular}{|c|c|c|c|}
\hline \multirow{2}{*}{} & \multicolumn{3}{|c|}{ IMPACT ON ACTUAL CONDITIONS } \\
\cline { 2 - 4 } & WORSENING & CONSERVATION & IMPROVEMENT \\
\hline WTP & negative & zero & positive \\
\hline WTA & positive & positive & positive \\
\hline Appropriate Measure & WTA & WTA & WTP \\
\hline
\end{tabular}

Within transport projects, many investments deal with the conservation of the current conditions. Indeed, transport infrastructure operation and maintenance are necessary in order to maintain a certain level of quality (e.g., travel time) that would otherwise be impossible to maintain due to the constant increase of traffic flows. These infrastructure investments can often be very expensive, depending on the transport network involved, and the convenience of the investment needs to be evaluated. In this case, the willingness to pay is expected to be zero since we are asking the users to face a situation where the quality of service remains stable at the actual level. Therefore, the user benefit associated with such investments should be calculated using their willingness to accept for a loss in service quality (e.g., an increase in the travel time) which would be the consequence if the investment were not realized.

The typical situation in the economic appraisal of a transport project is however the evaluation of an investment against an improvement of the actual condition. This is the case of a new transport infrastructure, where the willingness to pay is now positive and reflects the maximum (marginal) 
amount that consumers are willing to pay for the improvement (e.g., a reduction of the travel time). Therefore, the willingness to pay should be used in the computation of user benefits.

\subsection{Case Studies on freight transport}

Based on the estimates from models M3 and M4 (reported in Table 3) we illustrate the implication of WTA/WTP discrepancy in the case of hypothetical policy measures for freight transport in Switzerland. In particular, we compare two cost-benefit analyses (CBA) distinguishing between the two categories highlighted in Table 4, conservation and improvement, respectively.

We hypothesize two different large investments along the Gotthard corridor which is the most important link across the Alpine region. The first investment refers to the construction of a second "Gotthard road tunnel" increasing the number of lanes from two to four representing a significant improvement in terms of travel time and punctuality. The second investment consists of protective galleries and tunnels on the north and south access to the Gotthard road tunnel. This represents a maintenance intervention assuming that climate change leads to a dramatic increase of hazards.

Table 5 describes the case studies. We realistically assume for both projects an identical initial cost of 900 millions $\mathrm{CHF}^{10}$ and we set the annual maintenance cost to $50.000 \mathrm{CHF}$. The population is set to 650.000 units according to the Swiss transport policy goal regarding the yearly number of trucks foreseen to cross the road corridor after 2018. The infrastructure lifetime and the discount rate are assumed to be 50 years and 4.5 percent, respectively.

Table 5 Case studies assumptions

\begin{tabular}{lr}
\hline \multicolumn{2}{c}{ Setting } \\
\hline Initial Cost & 900.000 .000 \\
\hline Annual Maintenance Cost & 50.000 \\
\hline Discount rate & $4.5 \%$ \\
\hline Population & 650.000 \\
\hline \multicolumn{2}{c}{ Scenfrastructure lifetime (years) } \\
\hline \multicolumn{2}{l}{ Change in Time attribute } \\
\hline Change in Punctuality attribute & $10 \%$ \\
\hline
\end{tabular}

The hypothetical scenario envisages a reduction of freight travel time of 10 percent and an increase in the punctuality of the freight transport services of 1 percent. In the first case these improvements are due to the elimination of queues caused by the current bottleneck. In the second case we assume that the increasing hazards would cause an increase in the travel time and punctuality which could be avoided by the investments. Given this scenario and given the WTP and WTA estimates from models M3 and M4 (for convenience reported in Table 6) we calculate the average generalized cost of the actual transport services as described by logistics managers and the average generalized cost of the same transport services but under the scenario assumptions ${ }^{11}$, applying asymmetric WTP in the first

\footnotetext{
${ }^{10}$ The reference cost for the second "Gotthard road tunnel" is based on the estimate published in "Ticino Business", Camera di commercio, dell'industria, dell'artigianato e dei servizi del Cantone Ticino, Lugano, November 2008.

${ }^{11}$ The generalized cost is calculated as the sum of the cost, time and punctuality where time and punctuality are expressed in monetary values according to the WTP and WTA estimates.
} 
case and asymmetric WTA in the second case and, for comparison, symmetric WTP in both cases. The benefits for the freight transport sector associated to the hypothesised scenario are then derived by taking the difference of the generalized cost over the population considered ${ }^{12}$.

Table 6 Case studies results

\begin{tabular}{|c|c|c|c|}
\hline & $\begin{array}{c}\text { CASE } 1 \\
\text { IMPROVEMENT }\end{array}$ & $\begin{array}{c}\text { CASE } 2 \\
\text { MAINTENANCE }\end{array}$ & CASE 1 = CASE 2 \\
\hline & Asymmetric WTP & Asymmetric WTA & Symmetric WTP $=$ WTA \\
\hline Travel Time & 13.23 & 32.71 & 20.39 \\
\hline Punctuality & 36.30 & 152.22 & 79.16 \\
\hline Net Present Value & - 57 millions & 1,988 millions & 698 millions \\
\hline
\end{tabular}

These results shown in Table 6 demonstrate the relevance of estimating WTP and WTA separately and applying them appropriately. Using the traditional approach, and hence overestimating WTP for an improvement and underestimating WTA for maintenance, both projects would be accepted. Applying asymmetric WTP for the improvement results in a negative net present value demonstrating that 900 millions investment is not justified for a $10 \%$ and a $1 \%$ percent improvement in travel time and punctuality, respectively. On the other hand, an equally expensive maintenance investment with same impact is largely justified. In a general sense it is therefore demonstrated that applying symmetric WTP may lead in different contexts to significant over or under investments.

\section{Conclusions}

This paper has investigated the policy implications of WTA/WTP discrepancy in a freight transport context. The analysis has focused on the estimation of discrete choice models for two freight transport stated choice experiments. In particular, we estimated a set of random parameters logit models comparing between the classic symmetric specification which does not distinguish between WTP and WTA, and the reference dependent specification which relaxes the symmetry assumption allowing for the estimation of different parameters associated to gains and losses. We outlined then the policy implications supporting the discussion with hypothetical examples on the freight transport sector in Switzerland.

The results show that the reference dependent specification outperforms the symmetric specification and they prove the robustness of a reference dependent specification for datasets designed to accommodate different attribute level ranges. Loss aversion has been registered for all attributes investigated in the analysis leading to a significant WTA/WTP discrepancy. As a consequence, our results confirm the findings reported in the recent research literature that is, that symmetric models tend to overestimate WTP values and to underestimate WTA values.

The policy implications associated with WTP and WTA measures estimated from reference dependent choice models are indeed interesting. The paper defined three main categories of infrastructure projects

\footnotetext{
${ }^{12}$ To be noted that in the computation of the benefits we did not distinguish for intra-country transports and transports that use the corridor as connection between different countries. Indeed, it is reasonable to assume lower WTP values for the latter transport segment. However, we are convinced that our estimates are still conservative since we fixed the population to 650.000 , the Swiss policy objective, representing around the 50 percent of the actual figure.
} 
labelled worsening, conservation and improvement, respectively. For each category, the two measures (WTP and WTA) have been discussed and the most appropriate measure for the evaluation of the investment has been selected. The focus has then been on two categories that typically reflect transport projects, that is, transport infrastructures aimed to conserve or to improve the actual quality of the service. We pointed out a major difference between these two categories suggesting that the infrastructures aimed to conserve the actual conditions should be evaluated using the consumers WTA (contradicting the current state-of-the-art which apply the WTP) whereas the infrastructures aimed to improve the actual conditions should be evaluated, as classic research literature states, using the consumers WTP. However, using symmetric WTP estimates will underestimate the benefit of the latter kind of investment. Based on reference dependent model estimates and given our distinction for the type of infrastructure we conclude that the evaluation of investments aimed to conserve (improve) the actual conditions is underestimated (overestimated) if current guidelines apply.

Finally, we strongly encourage policy oriented analysts to estimate reference dependent choice models appropriately derived from reference pivoted choice experiments. The persistence in using symmetric discrete choice models as an instrument for deriving marginal substitution effects for policy purpose might most probably lead to biased evaluation in the form of significant overestimation or underestimation of the economic benefits of transport projects.

\section{References}

Bateman, I., Munro, A., Rhodes, B., Starmer, C., Sugden, R., 1997. A test of the theory of referencedependent preferences. Quarterly Journal of Economics 112, 479-505.

Ben-Akiva, M., Bolduc, D., Bradley, M., 1993. Estimation of travel mode choice models with randomly distributed value of time. Transportation Research Record 1413, 88-97.

Brown, T.C., Gregory, R., 1999. Why the WTA-WTP disparity matters. Ecological Economics 28, 323-335.

Danielis, R., Marcucci, E., Rotaris, L., 2005. Logistics managers' stated preferences for freight service attributes. Transportation Research Part E 41(3), 201-215.

De Borger, B., Fosgerau, M., 2008. The trade-off between money and travel time: a test of the theory of reference-dependent preferences. Journal of Urban Economics 64, 101-115.

Graves, P.E., 2009a. If the large WTA-WTP gap for public goods is real (and there are good reasons to think so) conventional welfare measures are simply incorrect. The Selected Works of PHILIP E GRAVES, Available at: http://works.bepress.com/philip_graves/35.

Graves, P.E., 2009b. The WTA-WTP Gap and Welfare Measures for Public Goods. The Selected Works of PHILIP E GRAVES, Available at: http://works.bepress.com/philip_graves/41.

Fowkes, A.S., 2007. The design and interpretation of freight stated preference experiments seeking to elicit behavioural valuations of journey attributes. Transportation Research Part B 41(9), 966-980. 
Hanemann, M., 1991. Willingness to pay and willingness to accept: How much can they differ? The American Economic Review 81(3), 635-647.

Hensher, D.A., 2001. Measurement of the valuation of travel time savings. Journal of Transport Economics and Policy 35(1), 71-98.

Hensher, D.A., 2008. Empirical approaches to combining revealed and stated preference data: Some recent developments with reference to urban mode choice. Research in transportation Economics 23, 23-29.

Hensher, D.A., Greene, W.H., 2003. Mixed logit models: state of practice. Transportation 30(2), 133176.

Hess, S., Rose, J.M., Hensher, D.A., 2008. Asymmetric preference formation in willingness to pay estimates in discrete choice models. Transportation Research Part E 44(5), 847-863.

Horowitz, J., McConnell, K.E., 2002. A Review of WTA-WTP Studies. Journal of Environmental Economics and Management 44, 426-47.

Kahneman, D., Tversky A., 1979. Prospect Theory: an analysis of decision under risk. Econometrica 47 (2), 263-291.

Mackie, P.J., Jara-Diaz, S., Fowkes, A.S., 2001. The value of travel time savings in evaluation. Transportation Research Part E 37(2-3), 91-106.

Maggi, R., Rudel, R., 2008. The Value of Quality Attributes in Freight Transport: Evidence from an SP-Experiment in Switzerland. In: Ben-Akiva, M.E., Meersman, H., van de Voorde E. (Eds.), Recent Developments in Transport Modelling. Emerald Group Publishing Limited.

Masiero, L., Maggi, R., 2009. Estimation of indirect cost and evaluation of protective measures for infrastructure vulnerability: A case study on the transalpine transport corridor. Quaderno N. 10-03, Faculty of Economics, University of Lugano.

Masiero, L., Hensher, D.A., 2010. Analyzing loss aversion and diminishing sensitivity in a freight transport stated choice experiment. Transportation Research Part A 44(5), 349-358.

McFadden, D., 1974. Conditional logit analysis of qualitative choice behavior. In: Zarembka, P. (Ed.), Frontiers in Econometrics. Academic Press, New York.

Train, K.E., Weeks, M., 2005. Discrete choice models in preference space and willingness-to-pay space. In: R. Scarpa and A. Alberini (Eds.), Application of simulation methods in environmental and resource economics. Springer Publisher, Dordrecht.

Randall, A., Stoll, J.R., 1980. Consumer's surplus in commodity space. The American Economic Review 70(3), 449-455.

Revelt, D., Train, K.E., 2000. Customer-specific taste parameters and mixed logit. WP E00-274, Department of Economics, University of California at Berkeley, CA. 
Rose, J.M., Masiero, L., 2009. A comparison of prospect theory in WTP and preference space. Institute of Transport and Logistics Studies, University of Sydney, October.

Train, K.E., McFadden D., Ben-Akiva, M., 1987. The demand for local telephone service: A fully discrete model of residential calling patterns and service choice. Rand Journal of Economics 18, 109123.

Tversky, A., Kahneman, D., 1991. Loss aversion in riskless choice: A reference-dependent model. Quarterly Journal of Economics 106, 1039-1061.

Tversky, A., Kahneman, D., 1992. Advances in Prospect Theory: Cumulative Representation of Uncertainty. Journal of Risk and Uncertainty 5, 297-323.

Zamparini, L., Reggiani, A., 2007. The value of travel time in passenger and freight transport: An overview. In: van Geenhuizen, M., Reggiani, A., Rietveld, P. (Eds.), Policy analysis of transport networks. Ashgate, Aldershot. 


\section{QUADERNI DELLA FACOLTÀ}

1998:

P. Balestra, Efficient (and parsimonious) estimation of structural dynamic error component models

1999:

M. Filippini, Cost and scale efficiency in the nursing home sector : evidence from Switzerland

L. Bernardi, I sistemi tributari di oggi : da dove vengono e dove vanno

L.L. Pasinetti, Economic theory and technical progress

G. Barone-Adesi, K. Giannopoulos, L. Vosper, VaR without correlations for portfolios of derivative securities

G. Barone-Adesi, Y. Kim, Incomplete information and the closed-end fund discount

G. Barone-Adesi, W. Allegretto, E. Dinenis, G. Sorwar, Valuation of derivatives based on CKLS interest rate models

M. Filippini, R. Maggi, J. Mägerle, Skalenerträge und optimale Betriebsgrösse bei den schweizerische Privatbahnen

E. Ronchetti, F. Trojani, Robust inference with GMM estimators

G.P. Torricelli, I cambiamenti strutturali dello sviluppo urbano e regionale in Svizzera e nel Ticino sulla base dei dati dei censimenti federali delle aziende 1985, 1991 e 1995

2000:

E. Barone, G. Barone-Adesi, R. Masera, Requisiti patrimoniali, adeguatezza del capitale e gestione del rischio

G. Barone-Adesi, Does volatility pay?

G. Barone-Adesi, Y. Kim, Incomplete information and the closed-end fund discount $\mathrm{R}$. Ineichen, Dadi, astragali e gli inizi del calcolo delle probabilità

W. Allegretto, G. Barone-Adesi, E. Dinenis, Y. Lin, G. Sorwar, A new approach to check the free boundary of single factor interest rate put option

G.D.Marangoni, The Leontief Model and Economic Theory

B. Antonioli, R, Fazioli, M. Filippini, // servizio di igiene urbana italiano tra concorrenza e monopolio

L. Crivelli, M. Filippini, D. Lunati. Dimensione ottima degli ospedali in uno Stato federale

L. Buchli, M. Filippini, Estimating the benefits of low flow alleviation in rivers: the case of the Ticino River

L. Bernardi, Fiscalità pubblica centralizzata e federale: aspetti generali e il caso italiano attuale

M. Alderighi, R. Maggi, Adoption and use of new information technology

F. Rossera, The use of log-linear models in transport economics: the problem of commuters' choice of mode

2001:

M. Filippini, P. Prioni, The influence of ownership on the cost of bus service provision in

Switzerland. An empirical illustration

B. Antonioli, M. Filippini, Optimal size in the waste collection sector

B. Schmitt, La double charge du service de la dette extérieure

L. Crivelli, M. Filippini, D. Lunati, Regulation, ownership and efficiency in the Swiss

nursing home industry

S. Banfi, L. Buchli, M. Filippini, Il valore ricreativo del fiume Ticino per i pescatori

L. Crivelli, M. Filippini, D. Lunati, Effizienz der Pflegeheime in der Schweiz 
2002:

B. Antonioli, M. Filippini, The use of a variable cost function in the regulation of the Italian water industry

B. Antonioli, S. Banfi, M. Filippini, La deregolamentazione del mercato elettrico svizzero e implicazioni a breve termine per l'industria idroelettrica

M. Filippini, J. Wild, M. Kuenzle, Using stochastic frontier analysis for the access price regulation of electricity networks

G. Cassese, On the structure of finitely additive martingales

2003:

M. Filippini, M. Kuenzle, Analisi dell'efficienza di costo delle compagnie di bus italiane e svizzere

C. Cambini, M. Filippini, Competitive tendering and optimal size in the regional bus transportation industry

L. Crivelli, M. Filippini, Federalismo e sistema sanitario svizzero

L. Crivelli, M. Filippini, I. Mosca, Federalismo e spesa sanitaria regionale : analisi empirica per i Cantoni svizzeri

M. Farsi, M. Filippini, Regulation and measuring cost efficiency with panel data models : application to electricity distribution utilities

M. Farsi, M. Filippini, An empirical analysis of cost efficiency in non-profit and public nursing homes

F. Rossera, La distribuzione dei redditi e la loro imposizione fiscale : analisi dei dati fiscali svizzeri

L. Crivelli, G. Domenighetti, M. Filippini, Federalism versus social citizenship : investigating the preference for equity in health care

M. Farsi, Changes in hospital quality after conversion in ownership status

G. Cozzi, O. Tarola, Mergers, innovations, and inequality

M. Farsi, M. Filippini, M. Kuenzle, Unobserved heterogeneity in stochastic cost frontier models : a comparative analysis

2004:

G. Cassese, An extension of conditional expectation to finitely additive measures

$\mathrm{S}$. Demichelis, O. Tarola, The plant size problem and monopoly pricing

F. Rossera, Struttura dei salari 2000 : valutazioni in base all'inchiesta dell'Ufficio federale

di statistica in Ticino

M. Filippini, M. Zola, Economies of scale and cost efficiency in the postal services :

empirical evidence from Switzerland

F. Degeorge, F. Derrien, K.L. Womack, Quid pro quo in IPOs : why book-building is dominating auctions

M. Farsi, M. Filippini, W. Greene, Efficiency measurement in network industries :

application to the Swiss railway companies

L. Crivelli, M. Filippini, I. Mosca, Federalism and regional health care expenditures : an

empirical analysis for the Swiss cantons

S. Alberton, O. Gonzalez, Monitoring a trans-border labour market in view of liberalization : the case of Ticino

M. Filippini, G. Masiero, K. Moschetti, Regional differences in outpatient antibiotic consumption in Switzerland

A.S. Bergantino, S. Bolis, An adaptive conjoint analysis of freight service alternatives : evaluating the maritime option

2005:

M. Farsi, M. Filippini, An analysis of efficiency and productivity in Swiss hospitals M. Filippini, G. Masiero, K. Moschetti, Socioeconomic determinants of regional differences in outpatient antibiotic consumption : evidence from Switzerland 
2006:

M. Farsi, L. Gitto, A statistical analysis of pain relief surgical operations

M. Farsi, G. Ridder, Estimating the out-of-hospital mortality rate using patient discharge data

S. Banfi, M. Farsi, M. Filippini, An empirical analysis of child care demand in Switzerland

L. Crivelli, M. Filippini, Regional public health care spending in Switzerland : an empirical analysis

M. Filippini, B. Lepori, Cost structure, economies of capacity utilization and scope in Swiss higher education institutions

M. Farsi, M. Filippini, Effects of ownership, subsidization and teaching activities on hospital costs in Switzerland

M. Filippini, G. Masiero, K. Moschetti, Small area variations and welfare loss in the use of antibiotics in the community

A. Tchipev, Intermediate products, specialization and the dynamics of wage inequality in the US

A. Tchipev, Technological change and outsourcing : competing or complementary explanations for the rising demand for skills during the 1980s?

2007:

M. Filippini, G. Masiero, K. Moschetti, Characteristics of demand for antibiotics in primary care : an almost ideal demand system approach

G. Masiero, M. Filippini, M. Ferech, H. Goossens, Determinants of outpatient antibiotic consumption in Europe : bacterial resistance and drug prescribers

R. Levaggi, F. Menoncin, Fiscal federalism, patient mobility and the soft budget constraint : a theoretical approach

M. Farsi, The temporal variation of cost-efficiency in Switzerland's hospitals : an application of mixed models

2008:

M. Farsi, M. Filippini, D. Lunati, Economies of scale and efficiency measurement in Switzerland's nursing homes

A. Vaona, Inflation persistence, structural breaks and omitted variables : a critical view

A. Vaona, The sensitivity of non parametric misspecification tests to disturbance autocorrelation

A. Vaona, STATA tip : a quick trick to perform a Roy-Zellner test for poolability in STATA

A. Vaona, R. Patuelli, New empirical evidence on local financial development and growth

C. Grimpe, R. Patuelli, Knowledge production in nanomaterials : an application of spatial filtering to regional system of innovation

A. Vaona, G. Ascari, Regional inflation persistence : evidence from Italy

M. Filippini, G. Masiero, K. Moschetti, Dispensing practices and antibiotic use

T. Crossley, M. Jametti, Pension benefit insurance and pension plan portfolio choice

R. Patuelli, A. Vaona, C. Grimpe, Poolability and aggregation problems of regional innovation data : an application to nanomaterial patenting

J.H.L. Oud, H. Folmer, R. Patuelli, P. Nijkamp, A spatial-dependence continuous-time model for regional unemployment in Germany

2009:

J.G. Brida, S. Lionetti, W.A. Risso, Long run economic growth and tourism : inferring from Uruguay

R. Patuelli, D.A. Griffith, M. Tiefelsdorf, P. Nijkamp, Spatial filtering and eigenvector stability : space-time models for German unemployment data

R. Patuelli, A. Reggiani, P. Nijkamp, N. Schanne, Neural networks for cross-sectional employment forecasts : a comparison of model specifications for Germany

A. Cullmann, M. Farsi, M. Filippini, Unobserved heterogeneity and International benchmarking in public transport

M. Jametti, T. von Ungern-Sternberg, Hurricane insurance in Florida

S. Banfi, M. Filippini, Resource rent taxation and benchmarking : a new perspective for the Swiss hydropower sector 
S. Lionetti, R. Patuelli, Trading cultural goods in the era of digital piracy

M. Filippini, G. Masiero, K. Moschetti, Physician dispensing and antibiotic prescriptions

2010:

Quaderno n. 10-01

R. Patuelli, N. Schanne, D.A. Griffith, P. Nijkamp, Persistent disparities in regional unemployment : application of a spatial filtering approach to local labour markets in Germany

Quaderno n. 10-02

K. Deb, M. Filippini, Public bus transport demand elasticities in India

Quaderno n. 10-03

L. Masiero, R. Maggi, Estimation of indirect cost and evaluation of protective measures

for infrastructure vulnerability : a case study on the transalpine transport corridor

Quaderno n. 10-04

L. Masiero, D.A. Hensher, Analyzing loss aversion and diminishing sensitivity in a freight transport stated choice experiment

Quaderno n. 10-05

L. Masiero, D.A. Hensher, Shift of reference point and implications on behavioral reaction to gains and losses

Quaderno n. 10-06

J.M. Rose, L. Masiero, A comparison of prospect theory in WTP and preference space Quaderno n. 10-07

M. Filippini, M. Koller, U. Trinkner, Do opening hours and unobserved heterogeneity

affect economies of scale and scope in postal outlets?

Quaderno n. 10-08

G. Guerra, R. Patuelli, R. Maggi, Ethnic concentration, cultural identity and immigrant self-employment in Switzerland

Quaderno n. 10-09

S. Lionetti, Tourism productivity : incentives and obstacles to fostering growth

Quaderno n. 10-10

G. Guerra, R. Patuelli, The influence of role models on immigrant self-employment : a spatial analysis for Switzerland

Quaderno n. 10-11

M. Filippini, L. Gonzalez, G. Masiero, Estimating dynamic consumption of antibiotics using panel data : the shadow effect of bacterial resistance

2011:

Quaderno n. 11-01

L. Masiero, J.L. Nicolau, Price sensitivity to tourism activities : looking for determinant factors

Quaderno n. 11-02

L. Masiero, J.L. Nicolau, Finding similar price preferences on tourism activities

Quaderno n. 11-03

L. Masiero, R. Maggi, Accounting for WTP/WTA discrepancy in discrete choice models : discussion of policy implications based on two freight transport stated choice experiments 